\title{
Observational case studies of treatment of skin disorders with natural phages in ganga water
}

\section{Bharat Jhunjhunwala', Rakesh Kumar Bhatnagar², Ashutosh Shukla ${ }^{3}$, Sanjay Kumar, Amit Patel $^{5}$, Jyotsana Khattri' ${ }^{2}$, Amit Kundu ${ }^{2}$, Madhvi Sanwelka ${ }^{2}$}

${ }^{1}$ Formerly, Indian Institute of Management, Bengaluru, India, ${ }^{2}$ Department of Pathology, National Institute of Medical Sciences and Research, Jaipur, India, ${ }^{3}$ Medical Practitioner, Gorakhpur, India, ${ }^{4}$ Medical Practitioner, Patna, India, ${ }^{5}$ Primary Heath Center, Rewati, Pratappur, Chhattisgarh, India

Corresponding author: Prof. Bharat Jhunjhunwala, E-mail: bharatjj@gmail.com

\begin{abstract}
Background: Skin conditions have multiple causes. Natural phages in the Ganga River have bactericidal qualities against a number of bacterial infections, which help resolve skin conditions. Materials and Methods: We collected water from upper reaches of the Ganga River where the number of isolates of phages was more than 200 according to a study of the National Environmental Engineering Institute, Nagpur. The water was collected in May 2020 before the onset of monsoons and stored with sediments so that the phages adsorbed in the sediments cleaned up the overlaying column of water of all coliforms. We supplied the water by post to a number of volunteers who took the water through oral, topical or nasal route as per their convenience. Thirty-nine of the 52 volunteers provided data by telephone on their skin conditions on which this study is based. Results: The results show that an improvement of 1.7 on Likert Scale of 1-10 is obtained on skin conditions as per assessment of the volunteers after a treatment of 100 days. Further improvement of 1.0 on Likert Scale was reported after 85 days of stoppage of treatment. Conclusions: Natural phages of Ganga river could provide an inexpensive treatment not only for skin conditions but other comorbidities as well because skin conditions have multiple causes and phages of Ganga water may work at multiple levels.
\end{abstract}

Key words: Phages; Dermatological Disorders; Microbiome

\section{INTRODUCTION}

The microbiome plays an important role in a wide variety of dermatological disorders [1]. Górski et al. have reported that anti-microbial action of phage may offer new perspectives for therapeutic application for various dermatological disorders [2]. Microorganisms including phages can enhance the immune responses in nonspecific ways. many pharmacological and immunological aspects of phages as medicines have not been established so far [3].

The National Environment Engineering Research Institute, Nagpur, India has reported that water of upper stretches of river Ganga contained more than 200 isolates of phages [4]. The Institute of
Microbial Technology has reported that variety of different phages, reported to have specific bactericidal activity against clinical isolates and pathogens like Mycobacterium, Streptococcus, Pseudomonas, Yersinia, Salmonella, Staphylococcus, Klebsiella, Vibrio, Shigella, Clostridium, Acinetobacter, Erwinia, Aeromonas, Escherichia, Cronobacter, Enterobacteria, and Campylobacter etc. are found in the Ganga waters [5]. These studies give us a reason to explore the use of phages in Ganga water for treating various skin disorders.

Historically, British bacteriologist Ernest Hankins observed antibacterial activity in Ganges and Yamuna waters against Vibrio cholera in 1986 [6]. At the same time French microbiologist, Felix D'Herelle observed

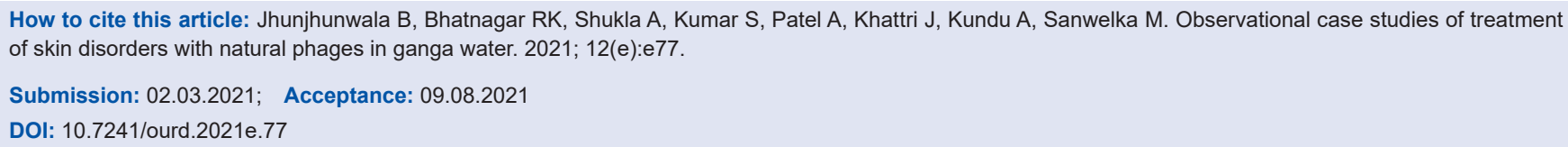


that even few feet below dead bodies (of people died with dysentery and cholera) floating in the Ganga, there were no germs at all. The factor conferring this unique antibacterial nature was also found to be thermo labile and thus, in due course, bacteriophages were first discovered in the Ganga river [7].

This paper reports studies the effect of Ganga water on various skin disorders, as phages in Ganga water could act upon a number of pathogenic microbiome and may help in improvement of various skin disorders. The specific objective of this study is to generate evidences for the effect of Ganga water on the skin disorders and build hypotheses to test with subsequent experimental studies [8].

\section{MATERIAL AND METHODS}

We collected water from upper reaches of the Ganga River in May 2020 before the onset of monsoons and stored with sediments so that the phages adsorbed in the sediments cleaned up the overlaying column of water of all coliforms. We supplied the water by post to a number of volunteers who took the water through oral, topical or nasal route as per their convenience. Thirty-nine of the 52 volunteers provided data by telephone on their skin conditions.

We have provided data obtained from volunteers in a longitudinal setting. More frequently this approach has been used for a large number of individuals [9]. We have adopted the same method for a smaller number of 39 volunteers as a pilot study. The study was based on a questionnaire filled-up by a researcher as told by the volunteer. Questions were asked about the symptoms related to the skin disorder at the beginning of the treatment and subsequently over time. This helped in obtaining a temporal sequence between the exposure to Ganga water and the outcome [10].

\section{Types of Studies}

We present a case series study and three case studies of volunteers included in the case series study [10]. Some volunteers in the present study were using other medication regimens in parallel [8]. We are aware that the effects of the given treatment tend to get mixed up and confounded by other time-dependent changes in such studies [8,9]. However, we have statistically isolated the effect of confounding medications.

\section{Scoring}

We have used a 1-10 Likert Scale [11,12], with "5" and less representing a morbid situation, and " 10 " representing best situation. We have undertaken regression analysis to assess the contribution of different parameters to the improvement in the skin disorder as reported by the volunteer.

We realize that the scores are not comparable between cases where the case himself/herself has given them. A "7" score by one person in a 1-10 scale may not mean the same as the same "7" score given by another person. However, we may assume that the same person would provide comparable score over time. Thus, the change is relatively more robust since the bias of the starting point is eliminated though the bias of the scale remains.

\section{Water Collection and Administration}

Water and sediments of upper stretches of the Ganga river was collected from Rudra Prayag above the confluence of Mandakini River. The water was collected in May 2020 before the onset of the monsoons because, as per our discussions with the scientists at the National Environment Engineering Research Institute, the numbers of phages are more before the monsoons.

As per Government Reports the Mean Dissolved Oxygen at this location is $9.6 \mathrm{mg} /$ liter and Mean Biological Oxygen Demand is $1.2 \mathrm{mg} /$ liter. Both these parameters are fit for drinking water. The $\mathrm{pH}$ is also reported to be within drinking water criteria of 6.5 to 8.5 though the figures are not given. The problem lies with coliforms that are reported at 9300 per $100 \mathrm{ml}$ against the requirement of $<50$ for drinking water [13]. We stored the water with sediments. We have found that the phages adsorbed into the sediments clean up the overlaying water column of all coliforms. We collected water in May 2020 and had it tested in February 2021. We found no coliforms. Hence the water is safe to drink. As reported below a number of volunteers have taken this water with no adverse results.

The water was stored in unused plastic containers. Growth of algae was observed in some containers that happened to be exposed to the sunlight in midAugust. The water was got tested. No fecal coliforms were found. However, growth of algae and fungus was observed. The water was then filtered to remove the algae and fungus. Sediment was thoroughly washed with filtered water and the washed sediment added to 
the filtered water. Hence adding the washed sediments to the filtered water reintroduced the phages adsorbed into the sediments into the water. This water was administered to volunteers orally, topically or nasally as per the convenience of the volunteer.

The volunteers administered Ganga water to themselves in three protocols.

1 Orally. The volunteer swished $10 \mathrm{ml}$ Ganga water in the mouth, breathed in with open mouth keeping the water in the mouth, then drank the water. This was done 2 or 3 times a day, at least half hour before or after meals.

2 Topical application on the affected area of the skin, 2 or 3 times a day.

3 Nasally by nebulizer for 5 minutes 2 or 3 times a day.

\section{Ethics Statement}

The author declare agreement with the 'statement of human and animal rights.'

\section{The Study}

Eighty volunteers were enlisted by sending message about a Natural Phage Therapy Project on social media. Volunteers were informed that high numbers of phages in Ganga water could help cure multiple morbidities/ disorders including skin disorders. They were requested to voluntarily administer Ganga water to themselves and record the effect on 10 morbidities namely, digestive, urological, neurological, metabolic, mental health, respiratory, cardiac, diabetes, skin disorders and arthritis on a scale of 1-10. Treated water was supplied to them by post. Data was available form 49 volunteers. Of these 10 volunteers did not provide data on their skin conditions. This study is based on the observations reported by the remaining 39 volunteers. Of these, two volunteers provided results of taking Ganga water in two bouts of take-stop-take-stop. These two bouts were treated as two separate observations making a total of 41 observations. Of these, 15 volunteers gave a level of 10 to their skin condition in the beginning indicating no chance of further improvement. Hence, we have undertaken two separate regression analysis-first for 41 observations including these 15 indicating beginning skin condition $=10$; and second for 26 observations including only those observations indicating initial skin condition less than 10 .

The volunteers were requested to take Ganga water in addition to their medical treatments. They were interviewed on phone between August 2020 and March 2021. They were requested to rank their health status on the 10 different disorders/morbidities mentioned above on a Likert Scale of 1-10. Interviews were done repeatedly after every 3-4 weeks. The volunteers were requested to again rank their status on the same 10 diseases on the scale of 1-10.

A number of volunteers stopped using Ganga water after a number of days because (1) they did not find and beneficial result; (2) they were satisfied with the result and found no reason to take the treatment any further; (3) because of inconvenience; or (4) other unspecified reasons. Data was available for 12 such volunteers and was used to assess whether the improvement/cure sustained or not.

Regression analysis was done with the change in the skin condition as the dependent variable and the following ten independent variables:

1 Numbers of days of treatment undertaken with Ganga water.

2 Initial level of the skin condition on 1-10 Likert scale.

3 Whether taking any confounding medicines? Yes $=1, \mathrm{~N}_{0}=0$.

4 Whether the volunteer was irregular in taking Ganga Jal. Yes $=1, \mathrm{No}_{0}=0$.

5 Male/Female, Female $=1$, Male $=0$.

6 Age in years.

7 Numbers of co-morbidities/disorders at the outset of study with less than 5 points on Likert Scale.

8 Oral intake $=1$, otherwise $=0$.

9 Topical application $=1$, otherwise $=0$.

10 Nasal intake $=1$, otherwise $=0$.

\section{RESULTS}

\section{Regression Analysis: Including Beginning Skin Condition $=10$}

We first made a regression analysis including the 39 cases (4l observations) with no skin ailments, that is, skin condition $=10$ on Likert Scale. The results are given at Table 1 .

Equation 1: All ten independent variables were included. The P-values of the last 5 parameters were greater than the benchmark 0.15 .

Equation 2: The oral and nasal methods of treatment were eliminated. The P-values of male-female, age and co-morbidities remained greater than 0.15 . 
Equation 3: Male-female and age were eliminated. The P-value of comorbidities remained greater than 0.15 .

Equation 4: Co-morbidities was eliminated. The P-values of the five independent variables were less than 0.20 with topical application at 0.186 .

Equation 5: Topical application was eliminated. The P-values of the remaining four independent variables, namely, days of treatment, start level, confounding medicine and irregular take were less than 0.15.

\section{Results for 26 Observations, Excluding Beginning Skin Condition $=10$}

We then made a regression analysis including only the 24 cases (26 observations) excluding those with no skin ailments, that is, skin condition $=10$ on Likert Scale. The results are given at Table 2 . The purpose was to focus on the cases that had some skin need.

Equation 1: All ten independent variables were included. The P-values of the last 5 parameters were greater than the benchmark 0.15 .
Equation 2: The oral and nasal methods of treatment were eliminated. The P-values of male-female, age and co-morbidities remained greater than 0.15 .

Equation 3: Male-female and age were eliminated. The P-value of comorbidities remained greater than 0.15 .

Equation 4: Co-morbidities was eliminated. The P-values of start level and topical application were greater than 0.15 with that for days of treatment, confounding medicines and irregular intake being less than 0.15 .

Equation 5: Start level was eliminated. The P-values of the remaining four independent variables, namely, days of treatment, confounding medicine, irregular take and topical application were less than 0.15 . We have discussed these results in detail in the "Discussion" section.

\section{Results after Stoppage of Treatment}

We lastly examined whether the improvements obtained by administering Ganga water sustained after stoppage of the treatment. Data for the skin condition after withdrawal of treatment was available for 12 out of

Table 1: Results of Regression Analysis, 41 observations (39 volunteers) including Skin Condition=10. The figures are of coefficients and $\mathrm{P}$-Values are given in brackets

\begin{tabular}{|c|c|c|c|c|c|c|c|c|c|c|c|c|}
\hline SI. No & $\begin{array}{l}\text { R-squared } \\
\text { (Adjusted } \\
\text { R-squared) }\end{array}$ & Intercept & $\begin{array}{l}\text { Days of } \\
\text { Treatment }\end{array}$ & $\begin{array}{l}\text { Start } \\
\text { Level }\end{array}$ & $\begin{array}{l}\text { Confounding } \\
\text { Medicine }\end{array}$ & $\begin{array}{l}\text { Irregular } \\
\text { Take }\end{array}$ & $\begin{array}{l}\text { Male }=0, \\
\text { Female }=1\end{array}$ & Age & $\begin{array}{l}\text { Numbers } \\
\text { of Co- } \\
\text { morbidities }\end{array}$ & Oral & Topical & Nasal \\
\hline 1 & 0.917 & $\begin{array}{l}0.565 \\
(0.519)\end{array}$ & $\begin{array}{l}0.010 \\
(0.000)\end{array}$ & $\begin{array}{l}-0.181 \\
(0.002)\end{array}$ & $\begin{array}{c}0.296 \\
(0.151)\end{array}$ & $\begin{array}{l}-1.762 \\
(0.000)\end{array}$ & $\begin{array}{l}0.085 \\
(0.716)\end{array}$ & $\begin{array}{l}0.005 \\
(0.451)\end{array}$ & $\begin{array}{c}0.047 \\
(0.264)\end{array}$ & $\begin{array}{l}-0.075 \\
(0.862)\end{array}$ & $\begin{array}{c}0.40 \\
(0.175)\end{array}$ & $\begin{array}{l}-0.275 \\
(0.451)\end{array}$ \\
\hline 2 & 0.915 & $\begin{array}{c}0.390 \\
(0.513)\end{array}$ & $\begin{array}{c}0.011 \\
(0.000)\end{array}$ & $\begin{array}{l}-0.178 \\
(0.000)\end{array}$ & $\begin{array}{c}0.305 \\
(0.126)\end{array}$ & $\begin{array}{l}-1.773 \\
(0.000)\end{array}$ & $\begin{array}{l}0.078 \\
(0.731)\end{array}$ & $\begin{array}{l}0.005 \\
(0.414)\end{array}$ & $\begin{array}{l}0.050 \\
(0.214)\end{array}$ & $\times$ & $\begin{array}{c}0.263 \\
(0.126)\end{array}$ & $x$ \\
\hline 3 & 0.913 & $\begin{array}{c}0.694 \\
(0.128)\end{array}$ & $\begin{array}{c}0.011 \\
(0.000)\end{array}$ & $\begin{array}{l}-0.176 \\
(0.000)\end{array}$ & $\begin{array}{c}0.348 \\
(0.064)\end{array}$ & $\begin{array}{l}-1.660 \\
(0.000)\end{array}$ & $\times$ & $\times$ & $\begin{array}{c}0.046 \\
(0.240)\end{array}$ & $x$ & $\begin{array}{c}0.391 \\
(0.135)\end{array}$ & $x$ \\
\hline 4 & 0.909 & $\begin{array}{c}0.868 \\
(0.048)\end{array}$ & $\begin{array}{c}0.012 \\
(0.000)\end{array}$ & $\begin{array}{l}-0.188 \\
(0.000)\end{array}$ & $\begin{array}{c}0.410 \\
(0.025)\end{array}$ & $\begin{array}{l}-1.659 \\
(0.000)\end{array}$ & $x$ & $x$ & $\times$ & $x$ & $\begin{array}{c}0.341 \\
(0.186)\end{array}$ & $x$ \\
\hline 5 & 0.904 & $\begin{array}{l}1.161 \\
(0.003)\end{array}$ & $\begin{array}{c}0.012 \\
(0.000)\end{array}$ & $\begin{array}{l}-0.224 \\
(0.000)\end{array}$ & $\begin{array}{c}0.453 \\
(0.013)\end{array}$ & $\begin{array}{l}-1.737 \\
(0.000)\end{array}$ & $x$ & $x$ & $x$ & $x$ & $\times$ & $x$ \\
\hline
\end{tabular}

Table 2: Results of Regression Analysis, 26 observations (24 volunteers) excluding Skin Condition=10. The figures are of coefficients and $\mathrm{P}$-Values are given in brackets

\begin{tabular}{|c|c|c|c|c|c|c|c|c|c|c|c|c|}
\hline SI. No & $\begin{array}{c}\text { R-squared } \\
\text { (Adjusted } \\
\text { R-squared) }\end{array}$ & Intercept & $\begin{array}{l}\text { Days of } \\
\text { Treatment }\end{array}$ & $\begin{array}{l}\text { Start } \\
\text { Level }\end{array}$ & $\begin{array}{l}\text { Confounding } \\
\text { Medicine }\end{array}$ & Irregular & $\begin{array}{c}\text { Male }=0, \\
\text { Female }=1\end{array}$ & Age & $\begin{array}{c}\text { Numbers } \\
\text { of Co- } \\
\text { morbidities }\end{array}$ & Oral & Topical & Nasal \\
\hline 1 & $\begin{array}{c}0.914 \\
(0.856)\end{array}$ & $\begin{array}{c}0.991 \\
(0.410)\end{array}$ & $\begin{array}{c}0.015 \\
(0.000)\end{array}$ & $\begin{array}{l}-0.006 \\
(0.944)\end{array}$ & $\begin{array}{c}0.237 \\
(0.457)\end{array}$ & $\begin{array}{l}-1.324 \\
(0.008)\end{array}$ & $\begin{array}{c}0.141 \\
(0.623)\end{array}$ & $\begin{array}{c}0.000 \\
(0.969)\end{array}$ & $\begin{array}{c}0.058 \\
(0.372)\end{array}$ & $\begin{array}{c}0.375 \\
(0.522)\end{array}$ & $\begin{array}{c}0.489 \\
(0.167)\end{array}$ & $\begin{array}{r}0.069 \\
(0.854)\end{array}$ \\
\hline 2 & $\begin{array}{c}0.911 \\
(0.869)\end{array}$ & $\begin{array}{l}-0.363 \\
(0.559)\end{array}$ & $\begin{array}{l}0.016 \\
(0.000)\end{array}$ & $\begin{array}{l}-0.043 \\
(0.510)\end{array}$ & $\begin{array}{c}0.345 \\
(0.188)\end{array}$ & $\begin{array}{l}-1.477 \\
(0.000)\end{array}$ & $\begin{array}{c}0.157 \\
(0.556)\end{array}$ & $\begin{array}{l}-0.000 \\
(0.941)\end{array}$ & $\begin{array}{l}0.044 \\
(0.439)\end{array}$ & $\times$ & $\begin{array}{c}0.342 \\
(0.176)\end{array}$ & $\times$ \\
\hline 3 & $\begin{array}{c}0.907 \\
(0.878)\end{array}$ & $\begin{array}{l}-0.351 \\
(0.461)\end{array}$ & $\begin{array}{l}0.015 \\
(0.000)\end{array}$ & $\begin{array}{l}-0.039 \\
(0.528)\end{array}$ & $\begin{array}{c}0.350 \\
(0.139)\end{array}$ & $\begin{array}{l}-1.394 \\
(0.000)\end{array}$ & $\times$ & $\times$ & $\begin{array}{c}0.050 \\
(0.354)\end{array}$ & $x$ & $\begin{array}{c}0.336 \\
(0.161)\end{array}$ & $x$ \\
\hline 4 & $\begin{array}{c}0.903 \\
(0.879)\end{array}$ & $\begin{array}{l}-0.170 \\
(0.693)\end{array}$ & $\begin{array}{c}0.016 \\
(0.000)\end{array}$ & $\begin{array}{l}-0.055 \\
(0.345)\end{array}$ & $\begin{array}{c}0.430 \\
(0.054)\end{array}$ & $\begin{array}{l}-1.395 \\
(0.000)\end{array}$ & $x$ & $x$ & $x$ & $x$ & $\begin{array}{c}0.271 \\
(0.231)\end{array}$ & $x$ \\
\hline 5 & $\begin{array}{c}0.899 \\
(0.879)\end{array}$ & $\begin{array}{l}-0.514 \\
(0.036)\end{array}$ & $\begin{array}{c}0.017 \\
(0.000)\end{array}$ & $x$ & $\begin{array}{c}0.364 \\
(0.081)\end{array}$ & $\begin{array}{l}-1.268 \\
(0.000)\end{array}$ & $x$ & $x$ & $x$ & $x$ & $\begin{array}{c}0.376 \\
(0.061)\end{array}$ & $x$ \\
\hline
\end{tabular}


26 observations that reported beginning skin condition $<10$, that is excluding beginning skin condition $=10$. The results are given at Table 3 .

Five volunteers reported no change while seven reported further improvement ranging from " 0.5 " to " 3 " with median of all observations at " 1 " at 85 days.

\section{Case Studies}

1. Female, 28 years, resident of Ghaziabad. She had not been taking any confounding medicines. She had suffered from ecchymotic patches on the skin eight years ago and they reappeared about one year ago with often times blood oozing out. She took Ganga water for 139 days by oral method and also applied topically to the affected parts of the skin. She reported improvement at $(+) 3$ level on skin condition. The wounds on the skin began to subside. Her data was recorded again 109 days after stopping the intake of Ganga water. She reported a further improvement at $(+) 3$ level on skin condition. The change in her skin condition can be seen at Figs. la and lb.

2. Female, 67 years, Resident of Mumbai. The volunteer has taken Ganga water for 205 days. She has been taking Ganga water orally and applying topically on the affected parts of the skin. She was suffering with thyroid, high blood pressure, diabetes and rheumatoid arthritis. She had been taking allopathic medicines for BP and diabetes. She had dark patches on her elbows for one year. The spots are totally gone as seen in the photos. She has not taken any medicine for the skin condition.

Table 3: Results after Stoppage of Treatment

\begin{tabular}{|c|c|c|c|c|c|}
\hline Number of observations & 5 & 1 & 4 & 1 & 1 \\
\hline $\begin{array}{l}\text { Average number of days after stoppage of } \\
\text { treatment that data was recorded. }\end{array}$ & 90 & 32 & 42 & 81 & 109 \\
\hline Change Scale 0-10 & 0 & 0.5 & 1 & 2 & 3 \\
\hline
\end{tabular}

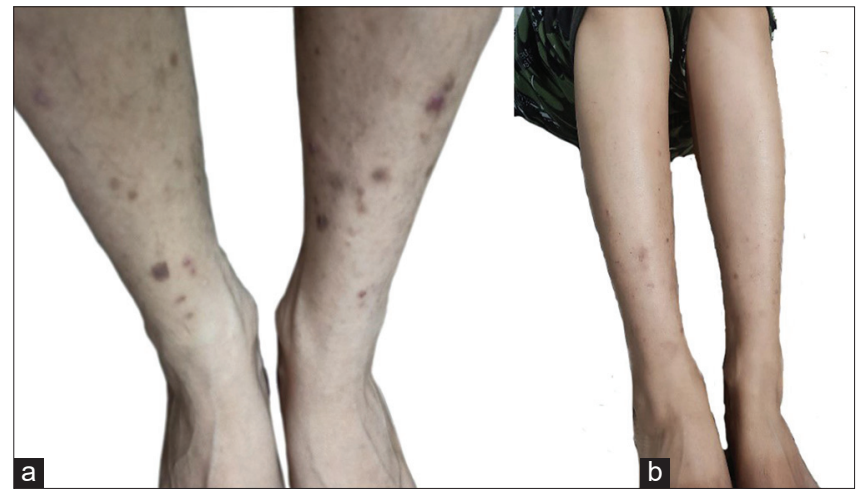

Figure 1: (a and b) Case Study 1: 22 July 2020/20 March 2021.
The improvement started to take place $1^{1 / 2}$ months after taking Ganga water. The change in her skin condition can be seen at Figs. 2a and 2b.

3. Male, 70 years, was not suffering from any major ailment. In Phase I, he took Ganga water by oral and nasal methods for 40 days. The skin spot on his right arm got much reduced. He also found benefits in urological and digestive functions. At the same time, however, he suffered from high BP. In Phase II, he stopped taking Ganga water for 81 days. The BP got normal. In Phase III, he applied Ganga water topically on both his arms for 91 days. The skin spot further reduced. He also found benefits in digestive and respiratory functions. In Phase IV, he stopped taking Ganga water for 60 days. The benefits obtained in Phase III sustained while there was further improvement in the skin discolouration/ rash. Photos of the skin spot at the beginning of Phase I are not available. The change in his skin condition from the beginning of Phase III and end of Phase IV are at Figs. $3 a$ and 3b.

\section{DISCUSSION}

The results given at last line of Table 2 and at Table 3 indicate that Ganga water can provide beneficial results especially if applied topically on the affected area of the skin. An improvement of 1.7 on scale of $1-10$ is obtained with the use of Ganga water for 100 days.

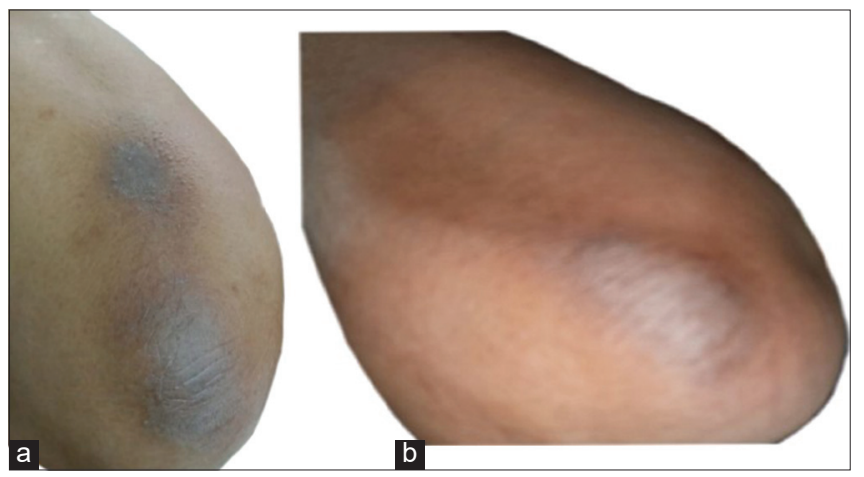

Figure 2: ( $a$ and b) Case Study 2: 1 August 2020/17 March 2021.

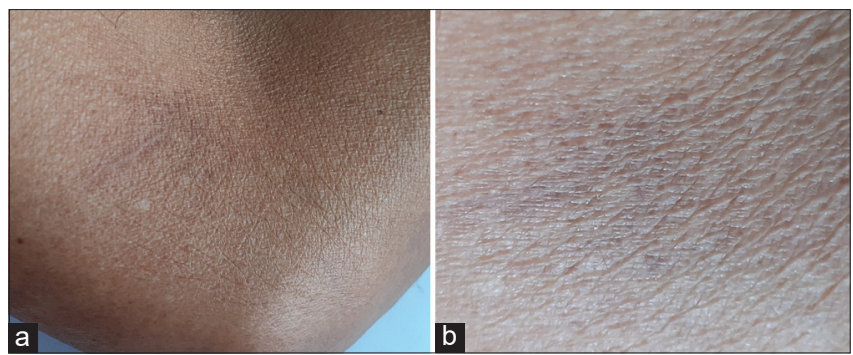

Figure 3: ( $a$ and b) Case Study 3: 1 July 2020/28 March 2021. 
A further improvement of 1 on scale of $1-10$ is obtained after 85 days of stopping treatment. Case studies 1 and 3 confirm that improvement continued to take place after stoppage of treatment.

Case study 3 suggests that there could have taken place an "over dose" of Ganga water through oral plus nasal methods leading to hemorrhage in the eyes. The same volunteer reported only benefits from topical application of Ganga water.

The results given at last line of Table 2 indicate that confounding medicines contribute to greater impact of Ganga water. Case study 2 supports this conclusion.

The results given at last line of Table 2 indicate that irregular intake of Ganga water reduces the beneficial impact. The volunteers in the three case studies all took Ganga water regularly with beneficial results.

The results given at last line of Table 2 as well as the three case studies indicate greater benefit of Ganga water on skin disorders when applied topically.

\section{CONCLUSION}

This study indicates that the phages in the water of the Ganga river could provide a simple and effective treatment for skin disorders as long as the treatment is taken regularly for and water is taken orally as well as applied topically. There is a need to undertake more detailed experimental studies [8].

\section{ACKNOWLEDGEMENTS}

Drs Narendra Nath Mehrotra, Amitabh Satsangi, Anil Gourishetty, Arvind Pandey, Sukhdev Singh and Surabhi Puri have provided valuable suggestions for improvement of the paper.

\section{Statement of Human and Animal Rights}

All procedures followed were in accordance with the ethical standards of the responsible committee on human experimentation (institutional and national) and with the Helsinki Declaration of 1975, as revised in 2008 .

\section{Statement of Informed Consent}

Informed consent was obtained from all patients for being included in the study.

\section{REFERENCES}

1. De Pessemier B, Grine L, Debaere M, Maes A, Paetzold B, Callewaert C. Gut-skin axis: current knowledge of the interrelationship between microbial dysbiosis and skin conditions. Microorganisms. 2021;9:353.

2. Gorski A, Bollyky PL, Przybylski M, Borysowski J, Miedzybrodzki R, Jonczyk-Matysiak E, et al. Perspectives of phage therapy in nonbacterial infections, Fron Microbiol. 2018;9:3306.

3. Manohar P, Tamhankar A J, Leptihn S, Ramesh N, Pharmacological and immunological aspects of phage therapy. Inf Microb Dis. 2019;1:2.

4. National Environment Research Institute, Untitled, 2018, page 5-44. Available from: URL: https://nmcg.nic.in/writereaddata/ fileupload/NMCGNEERI\%20Ganga\%20Report.pdf.

5. Institute of Microbial Technology, "Gangiomics: Unravelling the Unseen Phage Diversity in the Sediments of the Holy River Ganges through metagenomic approach," 2018.

6. Hankin EH. L'actionbact' ericide des eaux de la Jumna et du Gange sur le vibrion du chol'era. Ann Ins Pasteur. 1896;10:511-23.

7. Duckworth DH. Who discovered bacteriophage? Bacteriol Rev. 1976;40:793-802.

8. Sessler DI. Clinical research methodology 2: observational clinical research, Anesth Analg. 2015;121:1043-51.

9. Yorghos T, Nikolaos Z, Dynamic Factor analysis for multivariate time series: an application to cognitive trajectories. Int J Clin Biostat Biom. 2015;1:1.

10. Chidambaram AG, Josephson M. Clinical research study designs: The essentials. Pediatr Investig. 2019;3:245-52.

11. Versta Research, How to Label Your 10-Point Scale, Available from: URL: https://verstaresearch.com/blog/how-to-label-your10-point-scale/.

12. Decker F, How to Interpret Likert Surveys, Sciencing, March 2018, Available from: URL: http:// sciencing.com/interpret-likertsurveys-8573143.html.

13. Central Pollution Control Board, Pollution Assessment: River Ganga, 2103, Available from: URL: https://cpcb.nic.in/wqm/ pollution-assessment-ganga-2013.pdf.

Copyright by Bharat Jhunjhunwala, et al. This is an open access article distributed under the terms of the Creative Commons Attribution License, which permits unrestricted use, distribution, and reproduction in any medium, provided the original author and source are credited.

Source of Support: Administrative support was provided by Ganga Today

Trust, Conflict of Interest: None declared. 